\title{
Determination of superoxide dismutase mimetic activity in common culinary herbs
}

\author{
Magali Chohan ${ }^{1}$, Declan P Naughton² and Elizabeth I Opara ${ }^{2^{*}}$
}

\begin{abstract}
Background: Under conditions of oxidative stress, the removal of superoxide, a free radical associated with chronic inflammation, is catalysed by superoxide dismutase (SOD). Thus in addition to acting as an antioxidant, SOD may also be utilized as an anti-inflammatory agent. Some plant derived foods have been shown to have SOD mimetic (SODm) activity however it is not known if this activity is possessed by culinary herbs which have previously been shown to possess both antioxidant and anti-inflammatory properties. The aim of the study was to ascertain if the culinary herbs rosemary, sage and thyme possess SODm activity, and to investigate the influence of cooking and digestion on this activity. Transition metal ion content was also determined to establish if it could likely contribute to any SODm activity detected.
\end{abstract}

Findings: All extracts of uncooked (U), cooked (C) and cooked and digested (C\&D) herbs were shown to possess SODm activity, which was significantly correlated with previously determined antioxidant and anti-inflammatory activities of these herbs. SODm activity was significantly increased following (C) and (C\&D) for rosemary and sage only. The impact of (C) and (C\&D) on the SODm for thyme may have been influenced by its transition metal ion content.

Conclusions: SODm activity may contribute to the herbs' antioxidant and anti-inflammatory activities however the source and significance of this activity need to be established.

Keywords: Culinary herbs; Superoxide dismutase mimetic activity; Antioxidant; Anti-inflammatory

\section{Background}

The purported health promoting effects of culinary herbs may in part be due to their antioxidant and anti-inflammatory activities (Tapsell et al. 2006, Dhandapani et al. 2007, Lin and Lin 2008, Chohan et al. 2012, Baker et al. 2013). Culinary herbs are rich in polyphenols, which are the main contributors to their high antioxidant capacities (Zheng \& Wang 2001, Dragland et al. 2003, Halvorsen et al. 2006, Chohan et al. 2012). With regards to their anti-inflammatory activity, due to the complexity of the inflammatory response it is likely that these herbs elicit their anti-inflammatory activity via a number of pathways and mediators. Recent studies support this theory as culinary herbs have been shown to inhibit a range of pro-inflammatory mediators (Tsai et al. 2007, Chohan et al. 2012, Ho and Chang 2012, Kim et al. 2012, Baker et al. 2013).

\footnotetext{
* Correspondence: e.opara@kingston.ac.uk

${ }^{2}$ School of Life Sciences, Kingston University, Penrhyn Road, Kingston upon Thames KT1 2EE, UK

Full list of author information is available at the end of the article
}

The potent free radical superoxide $\left(\mathrm{O}_{2}^{*}\right)$, is produced as part of the acute inflammatory response and is a known modulator of this response (Halliwell et al. 1988, Guzik et al. 2003, Yasui and Baba 2006). However, overproduction of superoxide has been associated with chronic inflammation, which can contribute to the development of a number of chronic diseases including cardiovascular disease and cancer (Yasui and Baba 2006). The enzyme superoxide dismutase (SOD) is one of the most important cellular antioxidant enzymes in biological systems. It catalyses the removal of superoxide by dismutation into hydrogen peroxide $\left(\mathrm{H}_{2} \mathrm{O}_{2}\right)$ and oxygen, the $\mathrm{H}_{2} \mathrm{O}_{2}$ is then converted to water and oxygen by catalase. This action of SOD indicates that it may, in addition to being an antioxidant, be utilized as an anti-inflammatory agent (Yasui and Baba 2006). Studies have reported that plants and plant derived foods are able to either enhance or mimic SOD activity (Balaraman et al. 2004, Vouldoukis et al. 2004, Yoo et al. 2008, Thring et al. 2009, Candy et al. 2013, Carillon et al. 2013). Furthermore, this SOD mimetic (SODm) activity is associated with a 
decrease in pro-inflammatory mediators (Vouldoukis et al. 2004, Carillon et al. 2013). Therefore, such activity may contribute not only to the antioxidant property of culinary herbs but also to their anti-inflammatory activity. Thus, the aim of this study was to establish if common culinary herbs possess SODm activity. Furthermore, to address the possible influence of preparation and consumption, the effect of cooking and digestion on this activity was also investigated.

\section{Materials and methods Reagents}

All reagents were purchased from Sigma Aldrich, Poole, UK.

\section{Culinary herbs}

Rosemary (Rosmarinus officinalis), sage (Salvia officinalis) and thyme (Thymus vulgaris) dried were purchased from Neal's Yard Remedies, Richmond, Surrey, UK and stored as described in Chohan et al. (2012).

\section{Preparation of herb extracts}

Extracts of uncooked (U), cooked (C), cooked and digested in vitro $(\mathrm{C} \& \mathrm{D})$ and blank digests were prepared as previously described by the authors (Chohan et al. 2012).

\section{Preparation of standardised (STD) herb extracts}

A standardised amount of $30 \mathrm{mg} / \mathrm{mL}$ (STD) was prepared so as to determine the effect of cooking and digestion on the SODm activity of the same gram (g) amount of herb. These extracts were prepared as previously described by the authors (Chohan et al. 2012).

\section{Identification of SODm activity}

Herb extracts (U), (C), (C\&D) and (STD, uncooked), and their respective blanks were assessed for SODm activity using the nitroblue tetrazolium (NBT) assay (Fisher et al. 2003).

\section{Quantification of Transition Metal lons by Inductively Coupled Plasma-Atomic Emission Spectrometry (ICP-AES)} The content of redox-active transition metals of the herbs (U, C and C\&D), and their respective blanks, was established, using ICP-AES spectrometry (ULTIMA 2C, Jobin Yvon, France) to determine if correlations exist with SODm activities.

\section{Expression of data and statistical analysis}

Data are expressed as means \pm SD unless otherwise stated. Statistical analysis was carried out using SPSS for Windows. Results of the NBT (SODm) assay are presented as a percentage inhibition of formazan production by herb extracts. ANOVA and the post hoc Tukey test were used to compare SOD mimetic activities expressed in \% inhibition of formazan production for herbs $(U),(C),(C \& D)$ and STD. ANOVA and the post hoc Tukey test were used to compare the levels of metal ions $(\mu \mathrm{g} / \mathrm{g}$ of herb) for $(\mathrm{U})$, $(C)$ and $(C \& D)$ extracts and blank digests $(n=2)$. The level of significance is $\mathrm{p} \leq 0.05$.

\section{Results}

\section{SODm activity of herb extracts}

All the herb extracts possessed SODm activity, which was not diminished by cooking and digestion. The SODm activities (Table 1 ) of rosemary and sage $(\mathrm{U})$ were significantly lower than those of their $(C)$ counterparts $(\mathrm{p} \leq 0.05)$ and their $(C \& D)$ counterparts $(\mathrm{p}<0.05)$. There was no significant difference between the SODm for thyme $(\mathrm{U}),(\mathrm{C})$ and $(\mathrm{C} \& \mathrm{D})(\mathrm{p}=0.095)$. STD herbs possessed the highest SODm activities and all were significantly higher than those of their respective $(\mathrm{U}),(\mathrm{C})$ and $(C \& D)$ counterparts $(\mathrm{p} \leq 0.05)$ except for sage $(C \& D)$ $(p=0.068)$. To gain some insight into the possible sources and significance of SODm activity, the SODm values for the prepared samples were compared with their respective total phenolic content (expressed as gallic acid equivalence (GAE)), antioxidant capacity (expressed as trolox equivalence antioxidant capacity) and anti-inflammatory activity values (expressed as inhibition of interleukin- 8 release from human peripheral blood lymphocytes), which were previously published by the authors (Chohan et al. 2012) using Spearman rank correlation analysis. The analyses showed a significant association with GAE, TEAC, and \% inhibition of IL-8 release: $\left(\mathrm{r}_{s}=0.713, \mathrm{p} \leq 0.05\right.$ for SODm vs. estimated total phenolic content, $r_{s}=0.699$, $\mathrm{p} \leq 0.05$ for SODm vs. TEAC, $\mathrm{r}_{s}=0.713 \mathrm{p} \leq 0.05$ for SODm vs. inhibition of IL- 8 from PBLs exposed to TNF- $\alpha$, and $\mathrm{r}_{s}=0.622 \mathrm{p} \leq 0.05$ for SODm vs. inhibition of IL-8 from PBLs exposed to $\mathrm{H}_{2} \mathrm{O}_{2}$ ).

\section{ICP-AES analysis of herb extracts}

Although overall the $(C \& D)$ extracts had the highest individual transition metal ion contents, there was no clear and consistent pattern. However, out of the three herbs, thyme, for each treatment $(31.85 \mu \mathrm{g} / \mathrm{g}$, $42.33 \mu \mathrm{g} / \mathrm{g}$ and $47.96 \mu \mathrm{g} / \mathrm{g} \mathrm{U}, \mathrm{C}$ and C\&D respectively) had the highest total transition metal ions content based on the means of the constituent metal ions which was mainly due to their relatively high Mn content.

\section{Discussion}

The aim of this study was to determine if herbs known to possess antioxidant capacity and anti-inflammatory activity that are influenced by preparatory and digestive processes (Chohan et al. 2012) possess SODm activity, and if so how this activity is affected by these processes.

Extracts of all the herbs (C\&D) had higher amounts of $\mathrm{Cu}, \mathrm{Fe}, \mathrm{Mn}$, and $\mathrm{V}$ than their $(\mathrm{U})$ and $(\mathrm{C})$ counterparts, 
Table 1 SOD mimetic activities and ICP-AES data for uncooked (U), cooked (C) and cooked and digested in vitro (C\&D) herb extracts

\begin{tabular}{|c|c|c|c|c|c|c|c|}
\hline Sample & $\begin{array}{l}\text { SODm } \% \text { inhibition formazan } \\
\text { production }(n=3)^{a}\end{array}$ & $\begin{array}{c}\mathrm{Cu}(\mu \mathrm{g} / \mathrm{g}) \\
\mathrm{n}=\mathbf{2}\end{array}$ & $\begin{array}{c}\mathrm{Fe}(\mu \mathrm{g} / \mathrm{g}) \\
\mathrm{n}=2\end{array}$ & $\begin{array}{c}M n(\mu g / g) \\
n=2\end{array}$ & $\begin{array}{c}\mathrm{Ni}(\mu \mathrm{g} / \mathrm{g}) \\
\mathrm{n}=2\end{array}$ & $\begin{array}{c}V(\mu g / g) \\
n=2\end{array}$ & $\begin{array}{c}\mathrm{Zn}(\mu \mathrm{g} / \mathrm{g}) \\
\mathrm{n}=2\end{array}$ \\
\hline Rosemary (U) & $24.5 \pm 1.8$ & $0.69 \pm 0.05$ & $0.77 \pm 0.06$ & $2.96 \pm 0.03$ & $0.36 \pm 0.08$ & $1.13 \pm 0.04$ & $1.93 \pm 0.01$ \\
\hline Rosemary (C) & $32.9 \pm 1.4^{*}$ & $0.36 \pm 0.01$ & $0.57 \pm 0.03$ & $2.58 \pm 0.03$ & $0.31 \pm 0.11$ & $1.03 \pm 0.04$ & $1.71 \pm 0.04$ \\
\hline Rosemary $(C \& D)^{\mathbf{b}}$ & $38.6 \pm 3.9^{*}$ & $4.27 \pm 0.80^{* *}$ & $1.00 \pm 0.61$ & $10.39 \pm 1.72^{* *}$ & $0.56 \pm 0.14$ & $4.43 \pm 0.74^{* *}$ & $1.51 \pm 0.91$ \\
\hline Rosemary (STD) & $65.5 \pm 14.1$ & ND & ND & ND & ND & ND & ND \\
\hline Sage (U) & $19.5 \pm 4.5$ & $0.92 \pm 0.03$ & $1.33 \pm 0.04$ & $6.40 \pm 0.01$ & $0.11 \pm 0.15$ & $3.58 \pm 0.01$ & $7.11 \pm 0.09$ \\
\hline Sage (C) & $27.3 \pm 2.5^{*}$ & $1.29 \pm 0.03^{*}$ & $1.22 \pm 0.03$ & $6.40 \pm 0.33$ & $0.15 \pm 0.06$ & $3.58 \pm 0.12$ & $8.22 \pm 0.20^{*}$ \\
\hline Sage $(C \& D)^{\mathbf{b}}$ & $32.8 \pm 0.8^{*}$ & $2.36 \pm 0.02^{* *}$ & $5.61 \pm 0.04^{* *}$ & $12.32 \pm 0.14^{* *}$ & $0.01 \pm 0.00$ & $4.82 \pm 2.10$ & $7.29 \pm 0.13$ \\
\hline Sage (STD) & $58.3 \pm 18.6$ & ND & ND & ND & ND & ND & ND \\
\hline Thyme (U) & $36.9 \pm 6.2^{\mathrm{NS}}$ & $1.30 \pm 0.02$ & $2.02 \pm 0.00$ & $18.2 \pm 0.04$ & $0.27 \pm 0.15$ & $3.18 \pm 0.00$ & $6.88 \pm 0.06$ \\
\hline Thyme (C) & $31.9 \pm 1.5$ NS & $1.86 \pm 0.44$ & $2.68 \pm 0.46$ & $24.4 \pm 4.59$ & $0.40 \pm 0.14$ & $3.82 \pm 0.53$ & $9.17 \pm 1.72$ \\
\hline Thyme $(C \& D)^{\mathbf{b}}$ & $28.6 \pm 1.7^{\mathrm{NS}}$ & $3.09 \pm 0.75$ & $3.41 \pm 0.66$ & $26.28 \pm 1.77$ & $0.11 \pm 0.04$ & $6.78 \pm 0.40^{* *}$ & $8.29 \pm 0.99$ \\
\hline Thyme (STD) & $70.8 \pm 4.5$ & ND & ND & ND & ND & ND & ND \\
\hline
\end{tabular}

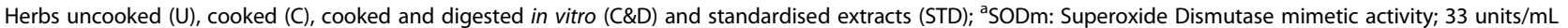
of SOD was used as a positive control $87 \% \pm 3.7$. 'blank digests values were subtracted from herbs values (C\&D). *significantly higher than (U) counterpart $(p<0.05)$, ** significantly higher than both $(U)$ and $(C)$ counterparts $(p<0.05)$; ${ }^{\text {NS }}$ no significant differences between thyme $(U),(C)$ and $(C \& D)(p=0.095)$. ND: not determined.

(although this was not always significant), and this may be due to the acid digestion of the herbs at the simulated gastric fluid stage causing the release of these metal ions. Transition metal ions are known to enhance oxidative damage by Fenton and Haber-Weiss reactions (Fisher and Naughton 2005). Phenolic acids with catechol groups, which are the polyphenols that predominate in the herbs investigated, have been shown to chelate transition metal ions to form complexes and thus decrease oxidative damage to cell membranes (Psotova et al. 2003). However, in the presence of oxygen and transition metal ions, the redox cycling of these phenolic acids can lead to the formation of reactive oxygen species. Furthermore, the pro-oxidant/antioxidant activity of transition metal ion/phenolic acid complexes that form as a result of this redox cycling, depends on the metal reducing properties and chelating abilities of the phenolic acids (Sakihama et al. 2002). Chohan et al. (2012) reported that $(C \& D)$ increases, significantly, the total phenolic content of rosemary, sage and thyme. Thus, based on the mechanism described above, with this increase in polyphenol content, an increase in the chelation and/or reduction of the metal ions should result in a decrease in antioxidant activity for (C\&D) herbs. However, the opposite occurred for the samples of rosemary $(C \& D)$ and sage $(C \& D)$ both in terms for their SODm activity (in the present study) and their antioxidant capacity (Chohan et al. 2012). It may be that the phenolic acids increased in insufficient quantities to reduce and/or chelate the transition metal ions and thus the balance was kept in favour of antioxidant activity. In the case of thyme $(C \& D)$, the balance in favour of antioxidant activity may have been compromised by pro-oxidant activity in the NBT assay, possibly generated by the higher levels of $\mathrm{Mn}$ and V, which may have occurred at the expense of SODm activity and thus may explain why this activity for thyme (C\&D) was lower compared to rosemary and sage $(C \& D)$ and not higher compared to its $(\mathrm{U})$ and $(\mathrm{C})$ counterparts.

The correlation analysis clearly shows that there is a strong and significant association between SODm activity in the herb samples and their respective GAE, TEAC and anti-inflammatory activity. Based on this analysis it is tempting to speculate that the herbs' polyphenols are sources of the SODm activity as suggested by Hunaefi and Smetanska (2013). This analysis also suggests that SODm activity contributes to the herbs' anti-inflammatory activity which is supported by the literature for other foods (Vouldoukis et al. 2004, Carillon et al. 2013). SODm activities were also assessed as a function of redox-active transition metal ion content (Fisher et al. 2003, Fisher and Naughton 2005) however no significant relationship was found.

\section{Conclusions}

In summary the current study shows that common culinary herbs possess SODm activity, which is not diminished by cooking and digestion. Correlation analysis suggests that this activity is associated with the herbs high polyphenol content, antioxidant capacity and anti-inflammatory action. Further work is required to fully determine its potential benefit in vivo as herbs are invariably consumed with a variety of foodstuffs and thus considerable scope exists for synergistic and antagonistic interactions with components released during digestion. 


\section{Competing interests}

The authors declare that they have no competing interests.

\section{Authors' contributions}

MC designed the study, carried out the experiments and data analysis, and assisted in the preparation of the manuscript. DPN assisted in the design of the study, and the preparation of the manuscript. ElO designed the study and prepared the manuscript. All authors read and approved the final manuscript.

\section{Acknowledgements}

MC was the recipient of a Biomedical and Pharmaceutical Sciences Research Group, Kingston University, funded Ph.D.

\section{Author details}

${ }^{1}$ School of Sport, Health and Applied Science, St Mary's University, Waldegrave Road, Strawberry Hill, Twickenham TW1 4SX, UK. ${ }^{2}$ School of Life Sciences, Kingston University, Penrhyn Road, Kingston upon Thames KT1 2EE, UK.

\section{Received: 11 July 2014 Accepted: 23 September 2014}

Published: 1 October 2014

\section{References}

Baker I, Chohan M, Opara El (2013) Impact of cooking and digestion, in vitro, on the antioxidant capacity and anti-inflammatory activity of cinnamon, clove and nutmeg. Plant Foods Hum Nutr 68:364-369

Balaraman R, Bafna PA, Kolhapure SA (2004) Antioxidant activity of DHC-1 - a herbal formulation. J Ethnopharmacol 94:135-141

Candy CSC, Waisundara V, Hoon LY (2013) Evaluation and Characterization of Antioxidant Activity of Selected Herbs and Spices. J of Nat Rem 13:95-103

Carillon J, Knabe L, Montalban A, Stévant MM, Keophiphath M, Lacan D, Cristol J-P, Rouanet J-M (2013) Curative diet supplementation with a melon superoxide dismutase reduces adipose tissue in obese hamsters by improving insulin sensitivity. Mol Nutr Food Res 58:842-850

Chohan M, Naughton DP, Jones L, Opara El (2012) An investigation of the relationship between the anti-inflammatory activity, polyphenolic content and antioxidant activities of cooked and in vitro digested culinary herbs. Oxid Med Cell Longev

Dhandapani KM, Mahesh VB, Brann DW (2007) Curcumin suppresses AP-1 and NFKB transcription factors. J Neurochem 102:522-538

Dragland S, Senoo H, Wake K, Holte K, Bolomhoff R (2003) Several culinary and medicinal herbs are important sources of dietary antioxidants. J Nutr 133:1286-1290

Fisher A, Naughton DP (2005) Therapeutic chelators for the twenty first Century: new treatments for iron and copper mediated inflammatory and neurological disorders. Curr Drug Deliv 2:261-268

Fisher AEO, Maxwell SC, Naughton DP (2003) Catalase and superoxide dismutase mimics for the treatment of inflammatory diseases. Inorg Chem Commun 6:1205-1208

Guzik TJ, Korbut R, Adamek-Guzik T (2003) Nitric oxide and superoxide in inflammation and immune function. J Physiol Pharmacol 54:469-487

Halliwell B, Hoult JR, Blake DR (1988) Oxidants, inflammation, and anti-inflammatory drugs. FASEB J 2:2867-2873

Halvorsen BL, Carlsen MH, Phillipis KM, Bøhn SK, Jacobs DR, Blomhoff JR (2006) Content of redox-active compounds (i.e., antioxidants) in foods consumed in the United States. Am J Clin Nutr 84:95-135

Ho S-C, Chang P-W (2012) Inhibitory effect of several spices on inflammation caused by advanced glycation end products. Am J Plant Sci 3:995-1002

Hunaefi D, Smetanska I (2013) The effect of tea fermentation on rosmarinic acid and antioxidant properties using selected in vitro sprout culture of Orthosiphon aristatus as a model study. SpringerPlus 2:167, doi:10.1186/21931801-2-167

Kim JH, Gupta SC, Park B, Yadav VR, Aggarwal BB (2012) Turmeric (Curcuma longa) inhibits inflammatory nuclear factor (NF)-KB and NF-kB-regulated gene products and induces death receptors leading to suppressed proliferation, induced chemosensitization, and suppressed osteoclastogenesis. Mol Nutr Food Res 56:454-465

Lin C, Lin J (2008) Curcumin: A potential cancer chemopreventive agent? J Cancer Mol 4:11-16
Psotova J, Lasovsky J, Vicar J (2003) Metal-chelating properties, electrochemical behaviour, scavenging and cytoprotective activities of six natural phenolics. Biomed Pap 147:147-153

Sakihama Y, Cohen MF, Grace SC, Yamasaki H (2002) Plant phenolic antioxidant and prooxidant activities: phenolic-induced oxidative damage mediated by metals in plants. Toxicol 177:67-80

Tapsell LC, Hemphill I, Cobiac L, Sullivan DR, Fenech M, Patch CS, Roodenrys S, Keogh JB, Clifton PM, Williams PG, Fazio VA, Inge KA (2006) Health benefits of herbs and spices: the past, the present, the future. Supplement Med J Australia 185(4 suppl):S1-S24

Thring TSA, Hili P, Naughton PD (2009) Anti-collagenase, anti-elastase and anti-oxidant activities of extracts from 21 plants. Complement Altern Med 9:27, doi:10.1186/1472-6882-9-27

Tsai P-J, Tsai T-H, Yu C-H, Ho S-C (2007) Evaluation of NO-suppressing activity of several Mediterranean culinary spices. Food Chem Toxicol 45:440-447

Vouldoukis I, Lacan D, Kamate C, Coste P, Calenda A, Mazier D, Conti M, Duga B (2004) Antioxidant and anti-inflammatory properties of a Cucumis melo LC. J Ethnopharmacol 94:67-75

Yasui K, Baba A (2006) Therapeutic potential of superoxide dismutase for resolution of inflammation. Inflamm Res 55:359-363

Yoo KM, Lee CH, Lee H, Moon B, Lee CY (2008) Relative antioxidant and cryoprotective activities of common herbs. Food Chem 106:929-936

Zheng W, Wang SY (2001) Antioxidant activity and phenolic compounds in selected herbs. J Agric Food Chem 49:5165-51170

\section{doi:10.1186/2193-1801-3-578}

Cite this article as: Chohan et al:: Determination of superoxide dismutase mimetic activity in common culinary herbs. SpringerPlus 2014 3:578.

\section{Submit your manuscript to a SpringerOpen ${ }^{\circ}$ journal and benefit from:}

- Convenient online submission

- Rigorous peer review

- Immediate publication on acceptance

- Open access: articles freely available online

- High visibility within the field

- Retaining the copyright to your article

Submit your next manuscript at $>$ springeropen.com 